Volume 7, Aug 2008 - Jan 2009

Issue 2

\title{
Regulations and Ethical Considerations for Astronomy Education Research III: A Suggested Code of Ethics
}

\author{
by Erik Brogt \\ University of Arizona \\ Tom Foster \\ Southern Illinois University Edwardsville \\ Erin Dokter \\ University of Arizona \\ Sanlyn Buxner \\ University of Arizona \\ Jessie Antonellis \\ University of Arizona \\ Received: 07/07/08, Revised: 09/03/08, Posted: 11/11/08
}

The Astronomy Education Review, Issue 2, Volume 7:57-65, 2009

(C) 2008, Erik Brogt. Copyright assigned to the Association of Universities for Research in Astronomy, Inc.

\begin{abstract}
We present an argument for, and suggested implementation of, a code of ethics for the astronomy education research community. This code of ethics is based on legal and ethical considerations set forth by U.S. federal regulations and the existing code of conduct of the American Educational Research Association. We also provide a fictitious research study as an example for working through the suggested code of ethics.
\end{abstract}

\section{INTRODUCTION}

Astronomy education research is a growing and maturing field of study. As discussed in earlier articles (Brogt, Dokter, \& Antonellis 2007; Brogt, Dokter, Antonellis, \& Buxner 2008, hereafter Paper I and Paper II, respectively), practitioners in the field may not be aware that our work in the United States is guided by federal and ethical requirements for sociobehavioral research. In Paper I, we outlined the general legal and ethical rules that govern researchers situated at institutions that receive any federal funding for research involving human participants. In Paper II, we provided details on the institutional review board (IRB) approval process and gave worked examples for various situations. 
We believe that all members of a research community should uphold their discipline's standards. By adhering to such standards, researchers indicate that they are conducting their scholarly efforts in a manner consistent with accepted research ethics. However, it is the responsibility of each discipline to establish these standards and develop a code of research ethics. In Section 2, we outline a call to our community to create, and adhere to, a standard code of ethics in astronomy education research. In Section 3, we suggest elements of a code of ethics based on U.S. federal regulations and the code of conduct of the American Educational Research Association (AERA). In Section 4, we give a practical example of a study that takes these elements into consideration. We make concluding remarks in Section 5.

\section{CALL FOR A CODE OF ETHICS}

In astronomy education research, as in astronomy and other scholarly endeavors, we aim to expand human knowledge. However, unlike astronomers, astronomy education researchers collect data from or about individuals, who have legal and ethical protections as well as free will. We must take care to honor the trust that our participants place in us when they choose to take part in our research, by being conscientious of what we ask them to do and why.

What is considered ethical behavior in research has, in many cases, been left to personal and subjective opinion; as such, what one person determines to be acceptable behavior may cross a line for someone else. The decision about what constitutes acceptable research practice with studies involving other people, therefore, has been shifted away from the individual researcher. In the United States, the Belmont Report (National Commission for the Protection of Human Subjects 1979) is the federal regulation on which policies of individual IRBs are based (see Paper I). This regulation was borne out of such documents as the Nuremberg Code of 1947 (see, e.g., National Institute of Health, Office of Human Subjects Research n.d.) and the Helsinki Declaration of 1964 (see, e.g., World Medical Organization 1996), which were designed to protect individuals from coerced and cruel medical experimentation, and out of condemnation of sociobehavioral research with harmful outcomes for participants, such as the Stanford prison experiment (Haney, Banks, \& Zimbardo 1973) and the Milgram experiment (Milgram 2004). Protecting ourselves and our participants by adhering to an external rather than a personal frame of reference is the safest way to ensure high-quality, ethical research practice.

Another ethical consideration is the fact that many researchers in the field of astronomy education research are educators as well. This relationship creates additional ethical obligations, because we are morally and often contractually obligated to provide the best education we can possibly give. This "moral contract" must be foremost on the mind of any researcher who is also an educator in the setting in which he or she is conducting research. There is a power differential in these situations that must be monitored very carefully to avoid coercing individuals into participating in research studies or compromising their educational experience. Individuals are never obliged to participate, and this must be respected. After all, they come to these settings to learn, not to be research subjects.

As a community of practice, it is we who ultimately determine what constitutes quality research in our field. However, as education researchers in the United States, we are also accountable to the legal guidelines established by federal regulations. Furthermore, as researchers in the field of astronomy education, we are part of a greater education research community. In the United States, this community is professionally represented by the AERA, much as the American Astronomical Society professionally represents American astronomers. The AERA has acknowledged that there are fundamental ethical considerations that extend beyond those set forth by U.S. federal regulations. Although we fully endorse 
the AERA's code of conduct and consider it to be inclusive of our work, we felt that a smaller and more focused code of ethics specific to the astronomy education research community was required to initiate a discussion about what our community deems to be ethically acceptable research practice.

\section{A SUGGESTED CODE OF ETHICS FOR ASTRONOMY EDUCATION RESEARCH}

Next, we present our suggested code of ethics for the astronomy education research community. Our suggestions are based on three main sources: two U.S. federal regulations, and the AERA's code of conduct. These are:

- Code of Federal Regulations, Title 45: Public Welfare, Part 46: Protection of Human Subjects (U.S. Department of Health and Human Services 2005).

- Family Educational Rights and Privacy Act (U.S. Department of Education 1974).

- Ethical Standards of the American Educational Research Association (AERA 2000).

This suggested code of ethics is one means of further establishing astronomy education research as a mature research field.

\subsection{General Ethical Considerations and Responsibilities of the Field}

We propose that:

1. Astronomy educational researchers conduct their professional lives in such a way that they do not jeopardize future research, the public standing of the field, or the discipline's research results.

This statement is analogous to AERA Guiding Standard 1. Every practitioner has the responsibility to make sure that his or her work is conducted in a manner that illustrates the best of what astronomy education research can provide. This statement does not mean that we do not challenge each other's results or seek to discredit orthodoxies of the field, but that we always conduct our work in a professional manner.

2. Astronomy educational researchers honestly present evidence, findings, conclusions, and authorship.

This is analogous to AERA Guiding Standards 2 and 5. We would expect that no researcher in our field would fabricate, withhold, or falsify data, findings, or conclusions. We would expect researchers to report research findings as they are observed and interpreted to be. In research (and even in evaluations), there is an obligation to the truth and not to what the stakeholders or community expect. This standard also includes honest authorship of articles, by which authors on a paper are those researchers who have contributed significantly to the academic effort in the paper, and all authors are responsible for its content.

3. When writing for or communicating with nonresearchers, astronomy educational researchers carefully represent research findings. 
This is analogous to AERA Guiding Standard 7. We recommend ensuring that results are reported in a clear and unambiguous manner to avoid potential misunderstandings because research in the field may have implications for science education policy at high levels.

\section{Conflicts of interest be avoided.}

This is a variant of AERA Guiding Standard 10. Conducting or reviewing research in which the researcher or reviewer has a vested interest in the outcome is unethical. In addition, referees of papers should be fair and impartial.

\subsection{Research Procedures}

We propose that:

5. Astronomy educational researchers design research procedures in accordance with federal regulations, with special attention to the aspects listed below.

As mandated by federal regulation 45 CFR 46, if the research is conducted in settings with an institutional review board (IRB), researchers must ensure that they have IRB approval of their studies prior to commencing research (i.e., recruitment of participants). We recommend that those researchers without an IRB submit their research proposals for peer review by trusted and impartial colleagues, as illustrated in the example in Section 4. We refer to Paper I for a detailed description of IRB regulations (e.g., recruitment and consenting procedures, confidentiality, and privacy). The requirements at institutions with IRBs can be consulted for additional examples of this process.

\section{Informed consent be obtained from participants.}

Based on 45 CFR 46.111 and 46.116, potential participants need to know the following prior to participation: the purposes, procedures, risks, and benefits of the study; that their participation is voluntary; and that they can withdraw at any time without penalty. This also means that individuals who do not wish to participate cannot be placed in a control group. Individuals in a control group are part of the study, and informed consent must be obtained from these participants as well.

7. Confidentiality about participants and their data be maintained at all times.

Based on 45 CFR 46.111, participants' source data should be secure, and only study personnel are authorized to discuss personally identifying information pertaining to participants.

8. Researchers collect demographic data only as they pertain to the research question(s).

The privacy of participants as individuals needs to be respected at all times. Solicitation of personal information is inherently intrusive, and a theoretical rationale for collecting demographic data is always warranted. Funding agencies like NASA may require the collection of demographic data for evaluation or accounting purposes, and these data need to be treated with the utmost respect and confidentiality. 


\subsection{Research with Students}

We propose that:

9. Astronomy educational researchers conduct research in a manner that respects participants' learning.

Participants should not be disadvantaged educationally because of their participation. For instance, a research design in which the instructor uses a pedagogical technique that he or she does not believe is effective in order to provide a control against another section of students taught differently is ethically equivalent to withholding treatment and violates the Belmont Report's principle of beneficence.

10. Students' participation in astronomy education research in any educational setting or at any level be dissociated from assessment.

Students must be able to participate freely and voluntarily without fear of repercussions to their grades, future endeavors, letters of recommendation, or evaluations.

11. Astronomy educational researchers working with their own students be aware of the inherent power differential between instructor and student.

Students may not perceive that their participation in a study conducted by their instructor is voluntary and that they have the right to refuse to participate. Furthermore, such students might be more inclined to tell the researcher what they believe he or she wants to hear. Therefore, working with one's own students presents both ethical and research validity concerns.

12. Astronomy educational researchers conducting research in their own classes acknowledge that their role as an instructor takes precedence over their role as a researcher.

Conducting research does not excuse us from our pedagogical responsibilities to our students. In all ethical considerations, the researcher must put the needs of the students above his or her own professional agenda.

It should be noted that these standards apply to students not only in the classroom but also in any situation in which the researcher holds a position of authority over learners. Examples include teacher professional development workshops run by the researcher and demonstrations given by the researcher at a science center.

\section{IN PRACTICE: A WORKED EXAMPLE OF SETTING UP A STUDY}

Based on the preceding code of ethics, we will now illustrate its use in the planning of a theoretical research study. We will discuss both the ethical issues and the design of the study. For this example, we assume that the researcher is at an institution that does not have an IRB in place, so as not to confuse IRB regulation with the proposed code of ethics. In this example, the research is conducted by an instructor at a community college, with her own students as potential research participants. She teaches introductory 
astronomy and has noticed that the class has a large number of students majoring in law and policy. She considers that these future law and policy professionals may be those who make decisions about science and science education funding in the future, and their perceptions of science during their college years may have an impact on how they make decisions during their career. Out of this observation, she formulates two research questions: What perceptions do students in law and policy programs have about science, and how are those perceptions influenced by a college-level introductory astronomy course?

\subsection{Study Design and Methods}

The researcher now considers how to approach her research question. She considers three important ethical issues in designing her study: first, that the risks to her participants are minimized; second, that the anticipated benefits outweigh these risks; and third, that her obligations to her students in the educational setting are fulfilled. She identifies a multiple-choice survey in the literature, which has been rigorously tested and includes reliability and validity measures, giving her confidence that she has an instrument that will be recognized when she goes to publish her own results. This survey, she believes, will also pose very minimal risk to her participants. She decides to administer this instrument pre- and postinstruction to investigate the effect of her course on the perceptions of the students.

In line with Proposed Standard 8, she considers whether she needs to collect personally identifying information with the surveys, such as students' names. Collecting anonymous data is less invasive, but it will not give her the opportunity to match students' pre- and postinstruction surveys and interviews, reducing her ability to make connections between the two bodies of data. Because she needs to match the predata to the postdata in the surveys, collecting data anonymously is not feasible. Our researcher opts to ask students to write their student identification number on the survey rather than their name.

Our researcher is aware that surveys will not give her information on why students have certain perceptions of science, nor on how the course may influence those perceptions. She decides to supplement the survey data with interviews. Although this method increases the risk to her participants, she believes that the benefits obtained from having these additional insights outweigh any risks posed.

Now that she has a research design in mind, she considers whether it will interfere in any way with her students' educational experience. Because the surveys will take little class time and the interviews will take place outside of class, she is confident that Proposed Standards 9 and 12 are upheld. Thus, she believes that she is following through on her commitment to her students as an instructor.

\subsection{Recruitment}

The next item of consideration is the recruitment of participants. Because our researcher is teaching an introductory class herself, it is both convenient and relevant for her to recruit her own students to participate, provided she is careful about avoiding coercive measures. She develops two recruitment scripts: one for orally introducing the surveys in her class, and one for following up by e-mail or telephone with those who indicate on their surveys that they are interested in participating in interviews. In her script, she includes the relevant information that students will need to decide whether to participate in the research. She describes the research and its purposes and will be emphatic that students' participation is voluntary and in no way connected with their grades, in line with Proposed Standards 6 and 10, based on 45 CFR 46.116 a1, a2, a3, a8. This information is restated in her interview recruitment script and detailed further in the consent forms she creates: one to be attached to the surveys, and one to be given to 
interviewees when she meets with them one on one. She will submit the two scripts and two consent forms with her proposal so that the reviewers can evaluate what she intends to say to potential participants and ensure that she avoids coercing students during recruitment.

Our researcher considers compensating her interview participants for their time. She normally offers various opportunities for extra credit in her classes. Participating in the interviews could be one of the options, as long as it is not coercive and the workload and reward for other forms of extra credit are comparable. She decides, however, that she wants to avoid any blurring of the line between research and student grades. Instead, she decides to offer students who participate a small gift certificate to the coffee shop on campus.

\subsection{Data Confidentiality}

Participants' confidentiality must be assured at each stage of data collection, in line with 45 CFR 46.111 (Proposed Standard 7). The researcher will be administering and collecting surveys from all students, regardless of whether they have filled them out, so the students will not know who is participating and who is not. The surveys themselves have students' identification numbers instead of names, which is as close to anonymous as the researcher can get with her research design. However, if students are opting to be interviewed, they will need to provide contact information, which is certainly not anonymous. She decides to add a line to the final section of the survey, stating that the student identification numbers and contact information will be kept in a secure location where only the researcher will have access to it and that this information will be destroyed at the end of the study.

For the interviews, she will contact the interested participants one by one so that their identities during this stage of the research will be known only to her. She has a statement in the interview consent forms that personally identifying information will be removed from the interview data. Finally, she prepares an area in a locked cabinet, and she creates a password-protected folder on her computer where all raw data and identifying information will be contained, again in line with Proposed Standard 7.

\subsection{Research Proposal Submission and Peer Review}

Based on all the preceding considerations, our researcher prepares her research proposal, in which she describes the rationale for her study, her research design, the population from which she will be recruiting, and all the measures she has taken to protect participants and their data (see Paper II for guidance on preparing a proposal; we also recommend using the proposal applications for institutions with IRBs as a basis). She includes all her instruments and scripts so that the reviewers will know exactly what she is doing at each step of the study. Had the researcher been at an institution with an IRB, she would submit a proposal to this entity; however, because her institution does not have an established IRB, she solicits the assistance of colleagues who can review her proposal, in accordance with Proposed Standard 5. Our suggestion would be to approach individuals who can speak to the following roles: supervisor to the researcher; advocate on behalf of students; and fellow researcher familiar with the IRB approval process (note that these need not be mutually exclusive categories). Our researcher obtains the assistance of her own dean in the science department, the dean of curriculum and instruction for the college, and a colleague who has conducted research at state institutions and who has submitted research proposals to human subjects protection programs. Although these individuals would not be legally bound by, or liable for, any unethical research practices (the federal regulations do not apply to institutions that do not receive federal funds for research on human participants), this review process would preserve and uphold the 
ethical standards of the community.

In time, our researcher hears back from both deans, who generally approve of the proposed research but have several suggestions. One is concerned about the use of interviews, which are more personal and involve more potential risk than surveys. The reviewer suggests that the researcher enlist the assistance of a colleague to conduct the interviews with the astronomy students. He reminds the researcher that there is a power differential between herself and the students, as mentioned in Proposed Standard 11, and that the students may, consciously or not, tell her want she wants to hear to protect their status with her. The researcher agrees to this change and approaches a fellow instructor to conduct the interviews.

She is now ready to begin recruiting for her study. Once the study begins, she must conform to the study procedures as described in her updated proposal. However, research studies rarely remain unchanged from initial planning through completion, and educational research studies are no exception. Because the researcher is working with human participants, should she require any substantial changes to the recruitment, consent, or data collection methods, it is recommended that she seek input and additional approval for these changes, as required at institutions with IRBs.

\section{CONCLUSIONS}

Any discussion of ethics must be a rational and carefully considered discussion. Rarely are ethical decisions simple, and all are embedded in the context of the situation. We stress that as a community, we must be mindful of the needs of our participants with regard to the nature of our studies, the data we collect, and our purposes in doing so. In this article, we have offered our rationale for, and suggestions for the implementation of, a code of ethics for astronomy education research. We invite the community to consider this code, and we encourage comments and suggestions for improvement. In particular, we are interested in the community's views relating to (1) how to conduct research in institutions that do not have a formal IRB in place, and (2) how to uphold ethical standards (through peer review, submission guidelines, or other methods) in a field that is becoming more international.

\section{References}

American Educational Research Association. 2000, "Ethical Standards of the American Educational Research Association," retrieved September 7, 2007, from http://www.aera.net/uploadedFiles/About_AERA/Ethical_Standards/EthicalStandards.pdf.

Brogt, E., Dokter, E., \& Antonellis, J. 2007, "Regulations and Ethical Considerations for Astronomy Education Research," Astronomy Education Review, 6(1), 43. http://aer.noao.edu/cgi-bin/article.pl?id=242.

Brogt, E., Dokter, E., Antonellis, J., \& Buxner, S. 2008, "Regulations and Ethical Considerations for Astronomy Education Research II: Resources and Worked Examples," Astronomy Education Review, 6(2), 99. http://aer.noao.edu/cgi-bin/article.pl?id=257.

Haney, C., Banks, W. C., \& Zimbardo, P. G. 1973, "Interpersonal Dynamics in a Simulated Prison," International Journal of Criminology and Penology, 1, 69. 
Milgram, S. 2004, Obedience to Authority: An Experimental View, New York: HarperCollins.

National Commission for the Protection of Human Subjects of Biomedical and Behavioral. 1979, "The Belmont Report: Ethical Principles and Guidelines for the Protection of Human Subjects of Research," retrieved April 18, 2007, from http://www.hhs.gov/ohrp/humansubjects/guidance/belmont.htm.

National Institute of Health, Office of Human Subjects Research. n.d., "Nuremberg Code," retrieved September 2, 2008, from http://ohsr.od.nih.gov/guidelines/nuremberg.html.

U.S. Department of Education. 1974, "Family Educational Rights and Privacy Act," retrieved April 18, 2007, from http://www.ed.gov/policy/gen/guid/fpco/ferpa/index.html.

U.S. Department of Health \& Human Services. 2005, "Code of Federal Regulations, Title 45: Public Welfare, Part 46: Protection of Human Subjects," retrieved April 18, 2007, from http://www.hhs.gov/ohrp/humansubjects/guidance/45cfr46.htm.

World Medical Organization. 1996, "Declaration of Helsinki," British Medical Journal, 313(7070), 1448.

ÆR

$57-65$ 